\title{
A REVIEW OF EXPERIMENTAL STUDY OF POWER QUALITY MONITOR ON HARMONIC MEASUREMENT
}

\author{
Rashmi Athiya ${ }^{1}{ }^{凶}$, Dr. A.K. Sharma ${ }^{2}$ \\ ${ }^{1}$ Research scholar, ME (High Voltage Engg.), Jabalpur Engineering College, Jabalpur (M.P) 482011, \\ India \\ 2 Professor \& HOD, Department of Electrical Engineering, Jabalpur Engineering College, Jabalpur \\ (M.P) 482011, India
}

DOI: https://doi.org/10.29121/ijetmr.v7.i6.2020.719

Article Citation: Rashmi Athiya, and Dr. A.K. Sharma. (2020). A REVIEW OF EXPERIMENTAL STUDY OF POWER QUALITY MONITOR ON HARMONIC MEASUREMENT. International Journal of Engineering Technologies and Management Research, 7(6), 156-159. https://doi.org/10.29121/ijetmr.v7 .i6.2020.719

Published Date: 30 June 2020

Keywords:

Power Quality

Frequency Variations

Total Harmonic Distortions

\begin{abstract}
Power Quality Monitor has an important role for utility and engineers in recent years. In this review, we are studying to remove the disturbance that produce in power supply system which is used in residential and industrial appliances. It is very necessary that reduce the harmonic the power supply system for increase the working life of electrical system equipments.
\end{abstract}

\section{INTRODUCTION}

The harmonic reduce is very necessary because of its produce the disturbance in power supply system. A distribution system is consisting of circuits fed from common bus and distribution systems are varying with different type of loads such as residential and industrial, load density (urban or rural), construction (radial or network) and voltage level. Power quality is direct depend with distribution system and which directly affecting in nowadays.

The measurement of power quality measurement gives the result in monitoring system, which is used to characterize disturbances and power quality variations in supply system. In this paper, we discuss the various type of information using different type of monitoring system. Analysis and produce information are converted in useful form.

In this paper, following objectives are included:

- Describe the important types of power quality variations in supply system.

- Monitoring equipment is used to measurement of power quality variations in supply system.

- Tools describe for analysis and produce information during power quality measurement. 


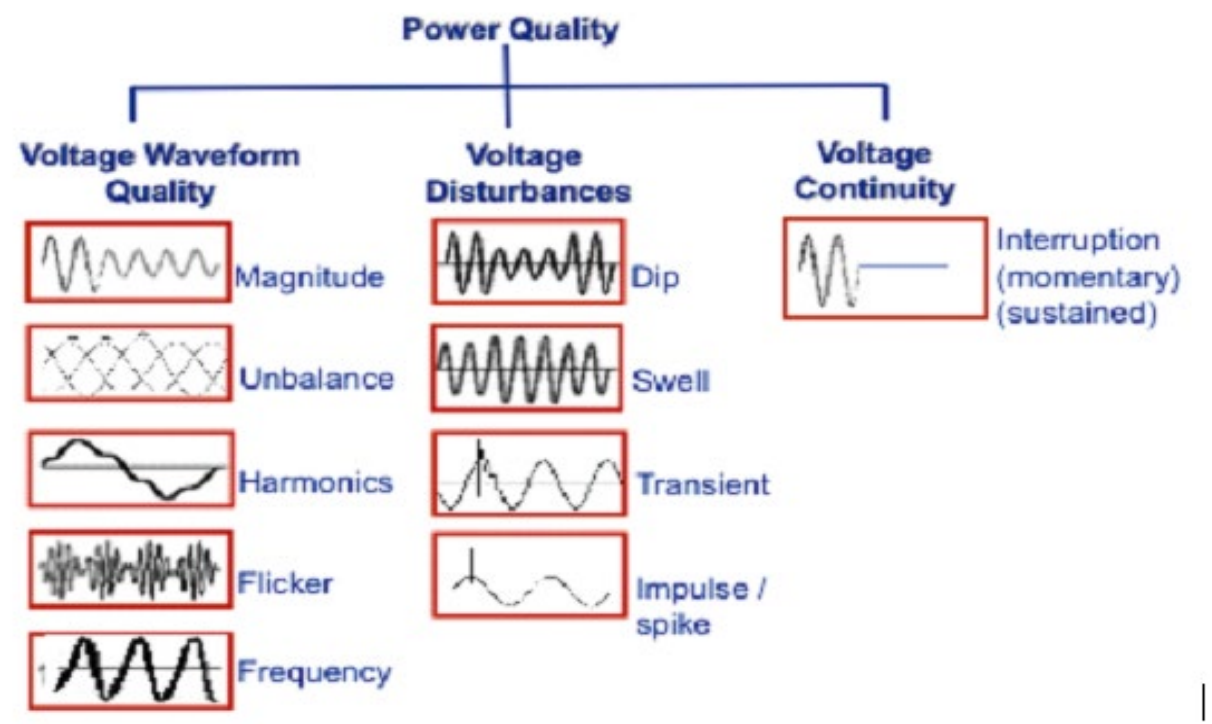

Figure 1: Power quality

\section{POWER QUALITY VARIATIONS}

First of all, we understand the power quality variation in supply system, which problem is generated with applied loads. The information is shared between various type of groups performance by measurement and its evaluation.

\subsection{DISTURBANCES}

The triggering are generated during abnormality in the voltage or the current supply, it is called disturbances in power supply system.

\section{RMS Variation}

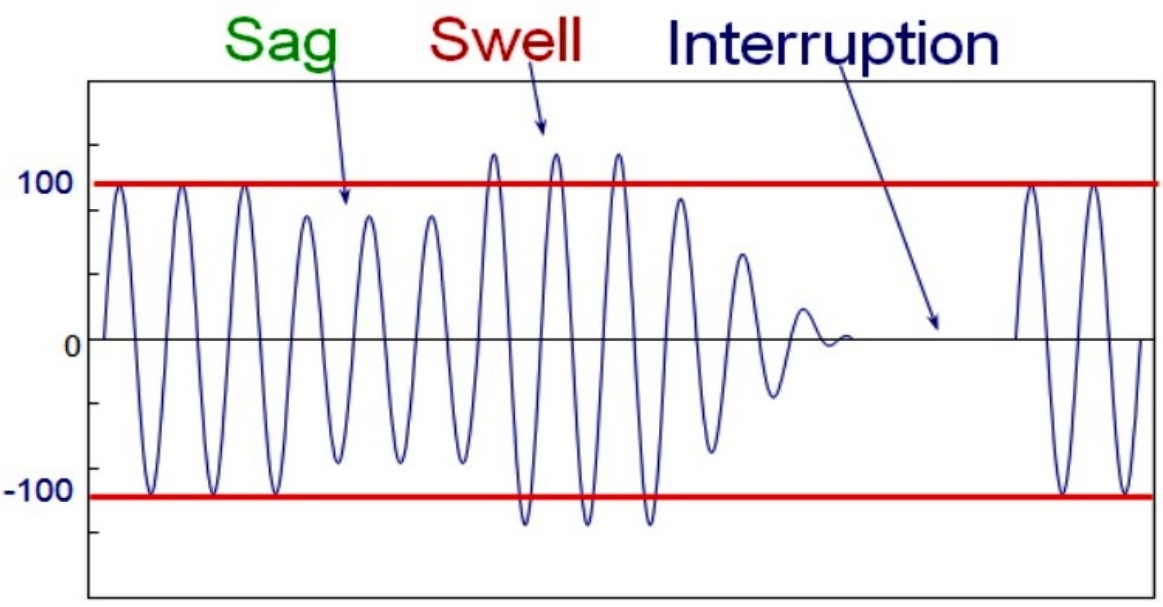

Figure 2: Disturbances

\subsection{STEADY STATE VARIATIONS}

In which included the normal RMS voltages variations and harmonic distortions in power supply system. These variations are very necessary for measurement using sampling voltage and/or current during time. 


\section{HARMONIC DISTORTION}

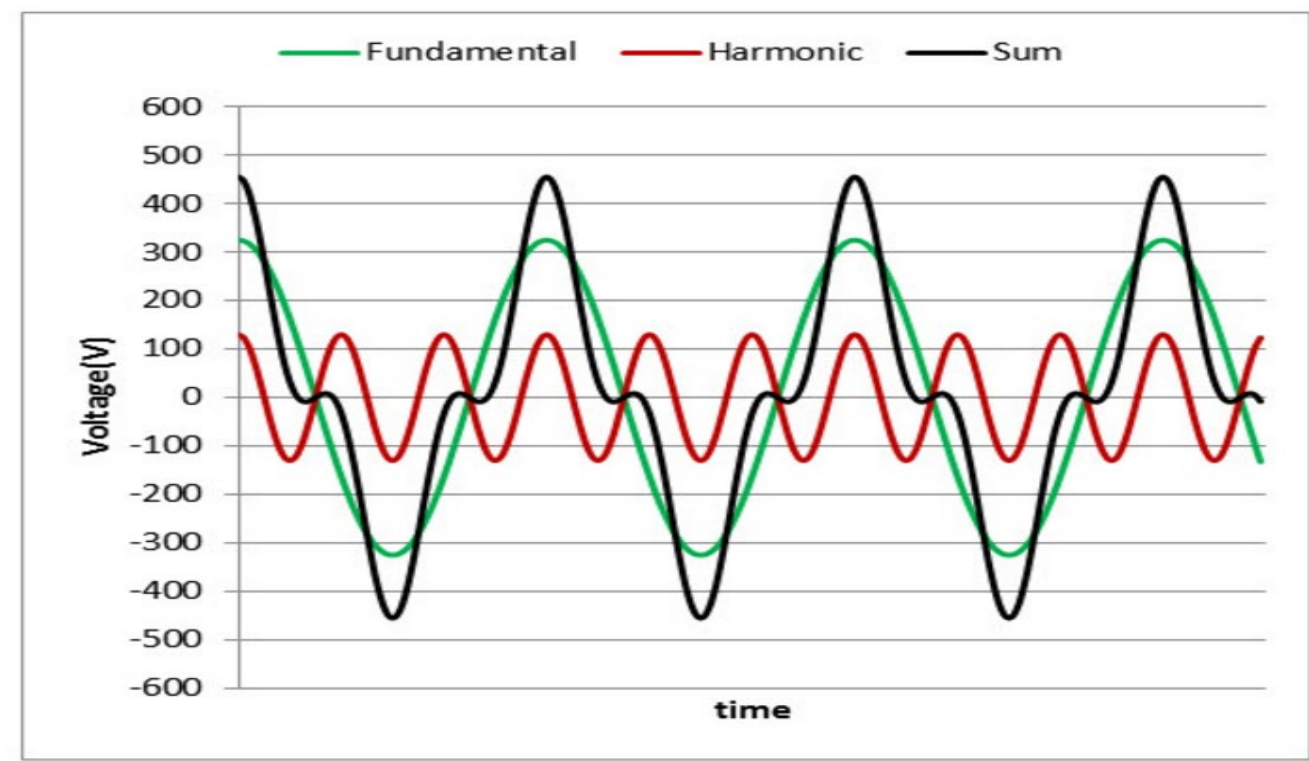

Figure 3: Harmonic Distortion

\section{MULTIMETERS OR DMMS}

- Phase-to-ground voltages

- Phase-to-neutral voltages

- Neutral-to-ground voltages

- Phase-to-phase voltages (three phase system)

- Phase currents

- Neutral currents

\section{CONCLUSION}

The various types of power quality variations are measured in power supply system and developed the evaluation procedures for measurement. The standardized measurements are used in evaluations in different systems. A data are analyzed for power quality measurements in system and to process data an instrument are used to support in processing the data.

\section{SOURCES OF FUNDING}

None.

\section{CONFLICT OF INTEREST}

None.

\section{ACKNOWLEDGMENT}

None. 


\section{REFERENCES}

[1] Mark F. McGranaghan, Surya Santoso and H. Wayne Beaty "Electrical Power Systems Quality" 2nd edition, McGraw-Hill Companies, 2004.

[2] Malcolm Barnes" Practical grounding, bonding, shielding and surge protection" Oxford: Newnes, 2004.

[3] Pedro Rodríguez “Grid Converters for Photovoltaic and Wind Power Systems” Wiley-IEEE Press, 2011. 